\section{Discussion}

This is the largest series so far to attempt to relate prenatal and perinatal factors to the subsequent development of growth hormone deficiency. The lack of any significant difference between the study group and the normal population with regard to the mode of delivery implies that the strong relation previously noted between traumatic deliveries and subsequent growth hormone deficiency no longer exists in the United Kingdom.

The higher number of boys suffering from growth hormone deficiency has been noted previously, ${ }^{1-3}$ although the ratio of affected boys to girls of 1.9:1 in this study is lower than the previous United Kingdom figure of $4: 1,{ }^{1}$ and lower than the accumulated ratio from other studies of $2 \cdot 8: 1{ }^{1}$ Growth hormone deficiency seems to be more common in boys than girls, but to what extent this is due to the fact that affected boys are more likely to seek medical attention is not clear.

As far as we know the significantly larger number of preterm and post-term deliveries in boys but not girls with growth hormone deficiency has not been described. Boys delivered preterm are more likely to suffer complications of prematurity than girls and, as cerebral hypoxia may damage the hypothalamopituitary tract, this may be another aetiological factor.

Our finding of significantly lower birth weights in children deficient in growth hormone requires further comment. Growth hormone is not thought to have an important role in fetal growth; indeed the previously described birth weights of British ${ }^{1}$ and American ${ }^{6}$ children with growth hormone deficiency were reported to be normal. The birth weights were, however, those reported by the mother rather than those obtained from birth records, and so they may not be accurate. There does not seem to be any other explanation for these findings as the heights of the parents were similar to those of the general population, and if the cause was placental insufficiency it is difficult to relate it to subsequent growth hormone deficiency. Unfortunately, birth lengths were not available: if these children had been significantly shorter than average this would have implicated growth hormone deficiency as the only aetiological agent rather than low birth weight.

We thank the directors of Growth Centres for permission to study data on their patients.

\section{References}

1 Rona RJ, Tanner JM. Aetiology of idiopathic growth hormone deficiency in England and Wales. Arch Dis Child 1977;52: 197-208.

2 Prader A, Zachman M, Poley JR, Illig R, Szeky I. Long term treatment with human growth hormone (Raben) in small doses. Evaluation of 18 hypopituitary patients. Helv Paediatr Acta 1967;22:423-40.

${ }^{3}$ Hubble D. Growth hormone deficiencies in childhood. Can Med Assoc J 1967;97:1144-58.

${ }^{4}$ MacFarlane A, Mugford M. Birth counts: statistics of pregnancy and childbirth. London: HMSO, 1984.

5 Tanner JM, Whitehouse RH, Takaishi M. Standards from birth to maturity for height, weight, height velocity and weight velocity: British children 1965. Part II. Arch Dis Child 1965;41:613-35.

${ }^{6}$ Brasel JA, Wright JC, Wilkins L, Blizzard RM. An evaluation of seventy five patients with hypopituitarism beginning in childhood. Am J Med 1965;38:484-98.

Correspondence to Dr S M Herber, Department of Paediatrics, Children's Hospital, Sheffield S10 2TH, England.

Received 15 January 1987

\title{
Neonatal lupus erythematosus, late onset hypocalcaemia, and recurrent seizures
}

\author{
A MOUDGIL, K KISHORE, AND R N SRIVASTAVA \\ Department of Paediatrics, All India Institute of Medical Sciences, New Delhi, India
}

SUMMARY A 6 day old infant had neonatal lupus erythematosus manifested by rash, haemolytic anaemia, and hepatosplenomegaly. His mother was asymptomatic until eight months of pregnancy. Between 7 and 10 weeks he had recurrent seizures with hypocalcaemia. Other causes of convulsions were excluded. By 14 weeks various abnormalities had largely disappeared.
Neonatal lupus erythematosus (NLE) is rare, about 100 cases having been reported. ${ }^{1}$ Its manifestations include rash, congenital heart block, and a variety of haematological and systemic abnormalities. ${ }^{1} \mathrm{Re}-$ cently, it has been recognised that Ro (SSA) antibodies, associated with Sjögren's syndrome, systemic lupus erythematosus (SLE), and other connective tissue diseases, are uniformly present in the blood of both infants who have NLE and their mothers who have SLE. ${ }^{1}$ This finding has led to a 
better understanding of NLE. We present a case of an infant with NLE who had recurrent seizures of late onset associated with hypocalcaemia. Such a feature has not been previously reported in NLE.

\section{Case report}

The boy was normally born at term after an uneventful pregnancy to a multigravida mother. His Apgar score was 9 at one minute and birth weight was $3400 \mathrm{~g}$. At birth he had a rash on the face, mainly in the periorbital region, with a few lesions on the trunk, and hepatosplenomegaly. The haemoglobin concentration was $13.9 \mathrm{~g} / \mathrm{dl}$ and platelet count $30 \times 10^{9} / 1$. He was given a blood transfusion and referred to this hospital.

The mother had developed an erythematous rash on the face during the eighth month of pregnancy, which had gradually increased. She had no other symptoms and had received no medication. Inquiry disclosed that all of her three previous babies had a rash similar to that of the present infant. The first baby had died at 3 days of age; the cause of death was not known. In the second infant the rash had begun to fade by 4 months and had disappeared over the next few weeks. He died of bronchopneumonia and gastroenteritis at 8 months. The third infant had convulsions at 2.5 months and died. Detailed laboratory investigations had not been carried out in these cases. The mother did not have a history of any important illness, rash, or intake of drugs during her earlier pregnancies.

On examination the baby had well marginated, erythematous, maculopapular, non-scaly lesions, $0.5 \mathrm{~cm}$ to $2 \mathrm{~cm}$ in diameter, mainly on the forehead and cheeks (Figure), with a few lesions on the trunk. The liver $(3.5 \mathrm{~cm})$ and spleen $(1 \mathrm{~cm})$ were enlarged. His general condition was satisfactory and examination of other systems yielded unremarkable results.

The mother had an erythematous, maculopapular, non-scaly rash on her face in a butterfly distribution. Itching and photosensitivity were absent. Systemic examination showed no abnormality.

Laboratory investigations in the baby. His haemoglobin concentration was $16.0 \mathrm{~g} / \mathrm{dl}$, leucocyte count $21 \times 10^{9} / 1$, with neutrophils $62 \%$, platelets $120 \times 10^{9} / 1$, and reticulocytes $20 \%$. Blood film showed evidence of haemolysis. Direct Coombs test yielded negative results. Serum albumin concentration was $45 \mathrm{~g} / \mathrm{l}$ and globulin $25 \mathrm{~g} / \mathrm{l}$. Serum glutamic oxalo-acetic transaminase, glutamic pyruvic transaminase, and alkaline phosphatase activities were normal. Blood tests for antibodies for toxoplasma, other viruses, rubella, cytomegalovirus, and herpes virus (TORCH) yielded negative results. An electrocardiogram (ECG) and an echocardiogram showed no abnormality. Bone marrow examination showed myeloid hyperplasia. A liver biopsy showed mild portal scarring and infiltration with chronic inflammatory cells and a skin biopsy showed hyperkeratosis and acanthosis. Antinuclear and Ro (SSA) antibodies were not detected in the blood (the specimen for the Ro (SSA) antibody was taken at 12 weeks).

Investigations in the mother. Her haemoglobin concentration was $8.7 \mathrm{~g} / \mathrm{dl}$. Leucocyte and platelet counts were normal and there was no evidence of haemolysis. Examination of her urine showed persistent $2+$ proteinuria and microscopic haematuria. Blood tests for rheumatoid factor, antinuclear antibodies, and TORCH group of antibodies yielded negative results; Ro (SSA) antibodies were detected along with weakly positive results for reticulin and gastric parietal cell antibodies. Skin biopsy findings were consistent with a diagnosis of lupus dermatitis. Renal biopsy examination showed moderately severe proliferative glomerulonephritis, with granular deposits of $\mathrm{IgG}$ and $\mathrm{C}_{3}$ along the capillary walls and in the mesangium.

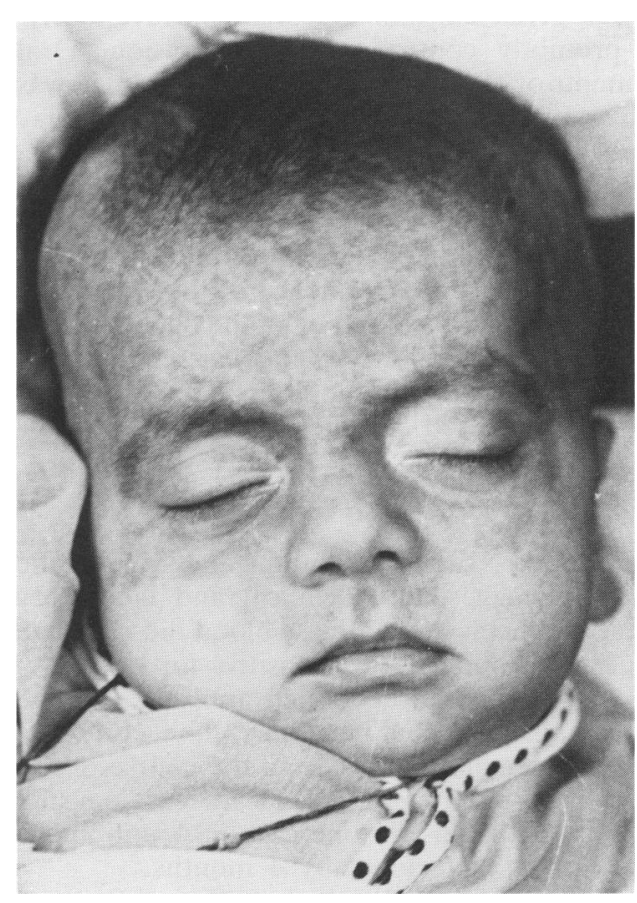

Figure Confluent rash on the forehead and discrete lesions on the cheeks, upper lip, and chin at 5 weeks of age. 
The laboratory findings supported a diagnosis of NLE in the infant and SLE in the mother.

Hospital stay. The baby showed evidence of continued haemolysis and he was given two blood transfusions. The rash initially increased and became confluent on the forehead but began to fade after the age of 6 weeks. At 7 weeks the boy started to have convulsions. There was generalised stiffness followed by a few jerky movements of the limbs and facial twitchings. These attacks lasted between two and five minutes and initially occurred between four and 10 times a day. Between the seizures he seemed to be well and took his feeds normally.

There was no focal neurological abnormality and he was afebrile. His blood pressure, optic fundi, cerebrospinal fluid, blood glucose and urea concentrations, $x$-ray films of skull, EEG, computed tomogram, and urinary aminoacid chromatogram showed no abnormality. At the onset of convulsions the serum calcium concentration was 1.5 $\mu \mathrm{mol} / \mathrm{l}$ and serum phosphorus concentration $2 \cdot 6$ $\mu \mathrm{mol} / \mathrm{l}$. Over the next few days, similarly abnormal values of serum calcium, ranging between 1.25 and $1.87 \mu \mathrm{mol} / \mathrm{l}$, and phosphorus, ranging between $2 \cdot 1$ and $2.9 \mu \mathrm{mol} / \mathrm{l}$, were found on five occasions. The baby had been exclusively breast fed.

He was given calcium gluconate intravenously, which promptly controlled the convulsion. Oral supplements of calcium lactate were started. He was also given prednisolone in a dosage of $2.5 \mathrm{mg} /$ day for three weeks, which was then tapered off. Convulsions recurred often during the next 10 days but thereafter decreased and stopped by 10 weeks, by which time the blood calcium and phosphorus concentrations had become normal. Blood reticulocytes were $2 \%$ and the haemoglobin concentrations were stable. The baby thrived and was sent home at 16 weeks in satisfactory condition. Hepatosplenomegaly had regressed and the rash largely cleared.

\section{Discussion}

A diagnosis of NLE in the infant and SLE in the mother was suggested by clinical and laboratory features. Although the mother's blood did not have antinuclear antibodies, it was positive for Ro (SSA) antibodies. The absence of such antibodies in the blood from the baby could be due to the fact that his blood was examined fairly late in the course of the disease. Most infants with NLE are serologically negative by 6 months; in one case SSA antibodies were no longer detectable by 4 months. ${ }^{2}$

Interestingly, the mother had no clinical features of SLE until the eighth month of her fourth pregnancy. It is now known that most mothers of infants with NLE are asymptomatic. ${ }^{1}$ They have an increased risk, however, of developing SLE or some other connective tissue disorder. In one instance the mother of three siblings who had congenital heart block developed SLE 16 years after the birth of the first of these infants. ${ }^{3}$

The main features of NLE are a characteristic rash and congenital heart block, which often do not occur together. ${ }^{4}$ Haemolytic anaemia and thrombocytopenia are seen in about $15 \%$ of cases; involvement of other systems is rare. ${ }^{1}$ Occurrence of seizures in our patient at 7 weeks was unusual. Exclusion of other causes of convulsions by detailed investigations, including EEG and computed tomography, and the repeated finding of hypocalcaemia suggested the latter as the responsible mechanism. Such a feature has not been previously reported in NLE. Hypocalcaemia could result from transient parathyroid deficiency, possibly due to antibody mediated injury. Unfortunately, we could not examine the blood for antiparathyroid antibodies.

Siblings born after an infant with NLE may be normal or have similar or different manifestations. ${ }^{1}$ The incidence of NLE in siblings of affected cases has been reported to be $19 \% .{ }^{5}$ Although laboratory tests were not performed in the previous three siblings in the present case, all of them possibly had NLE.

NLE, caused by passive transfer of maternal antibodies, is mostly self limited, and various manifestations except heart block usually disappear by about 6 months. ${ }^{2}$ Rarely, an infant with NLE may recover but then have SLE during adolescence. ${ }^{6}$ NLE should be considered in the diagnosis of a neonate who has rash, heart block, and unexplained haematological abnormalities or involvement of other systems. As in the present case, NLE may lead to detection of SLE in the mother.

We are grateful to Professor A N Malaviya and Dr A E Gharavi (Rayne Institute, St Thomas's Hospital, London) for immunological investigations.

\section{References}

1 Watson RM, Lane AT, Barnett NK, Bias WB, Arnett FC, Provost TT. Neonatal lupus erythematosus-a clinical, serological and immunogenetic study with review of the literature. Medicine (Baltimore) 1984;63:362-78.

2 Miyagawa S, Kitamura W, Yoskioka J, Sakamoto K. Placental transfer of anticytoplasmic antibodies in annular erythema of newborns. Arch Dermatol 1981;117:569-72.

3 Kasinath BS, Katz AI. Delayed maternal lupus after delivery of offspring with complete heart block. Arch Intern Med 1982;142:2317. 
${ }^{4}$ Hardy JD, Solomon S, Banwell GS, Beach R, Wright V, Howard FM. Congenital complete heart block in the newborn associated with maternal systemic lupus erythematosus and other connective tissue antibodies. Arch Dis Child 1979;54: $7-13$.

5 Lanham JG, Walport MJ, Hughes GRV. Congenital heart block and familial connective tissue disease. $J$ Rheumatol 1983;10: 823-5.

\footnotetext{
6 Jacksen R, Gulliver M. Neonatal lupus erythematosus progressing into systemic lupus erythematosus. $\mathrm{Br} J$ Dermatol 1979;101:81-6.
}

Correspondence to Dr R N Srivastava, Department of Paediatrics, All India Institute of Medical Sciences, New Delhi 110 029, India.

Received 4 December 1986

\title{
Multiple thromboses in systemic lupus erythematosus
}

\author{
S APPAN, M L BOEY, AND K W LIM \\ Department of Paediatrics, Tan Tock Seng Hospital, Singapore
}

SUMMARY A 5 year old girl with systemic lupus erythematosus developed extensive thromboses at multiple sites. Coagulation screen confirmed presence of the lupus anticoagulant. She recovered satisfactorily on high dose steroids without the use of anticoagulant treatment.

Patients with the lupus anticoagulant are known to have an increased tendency to develop thromboembolic complications. This has been reported only rarely, however, in young children. We report a case of extensive thrombosis in a 5 year old girl with systemic lupus erythematosus and autoimmune haemolytic anaemia.

\section{Case report}

A 5 year old Chinese girl first presented with a history of fever and progressive pallor for one month. Clinical examination revealed striking pallor, bilateral cervical lymphadenopathy, and hepatosplenomegaly.

Laboratory investigations showed a haemoglobin concentration of $3.7 \mathrm{~g} / \mathrm{dl}$, white blood cell count $16.9 \times 10^{9} / 1$ (polymorphs $79 \%$, lymphocytes $16 \%$, monocytes $2 \%$, eosinophils $1 \%$, and myelocytes $2 \%$ ), platelets $105 \times 10^{9} / 1$, reticulocytes $40 \%$, and erythrocyte sedimentation rate $170 \mathrm{~mm}$ in the first hour. Direct Coombs test yielded strongly positive results. Rheumatoid factor and lupus erythematosus cells were negative. Serum complement (total complement CH50) was 13 units (normal 30-40 units). Antinuclear antibody and anti-deoxyribonucleic acid (anti-DNA) (double stranded) antibody (haemagglutination test 1/32) were both positive (significant at $1 / 4$ and above). Complement binding IgG autoantibody was detected in the serum. Blood urea, electrolyte, and creatinine concentrations were normal. Urine microscopy yielded normal results.

A diagnosis of systemic lupus erythematosus with autoimmune haemolytic anaemia was made. The patient was treated with hydrocortisone and transfused with washed packed cells. She was discharged well, on treatment with oral prednisolone. After one month on a dosage of $2 \mathrm{mg} / \mathrm{kg} /$ day her blood counts were haemoglobin $12 \mathrm{~g} / \mathrm{dl}$, erythrocyte sedimentation rate $10 \mathrm{~mm}$ in the first hour, serum complement 33 units, and antinuclear and anti-DNA antibodies negative. A direct Coombs test yielded negative results. The steroid dosage was gradually tailed down to $5 \mathrm{mg}$ every other day and she was maintained on this dose for one year. As she remained well both clinically and serologically and had no other organ involvement the steroid dosage was further tailed down and finally stopped. She was followed up closely and her blood counts and serological markers were within normal limits.

Three months after the treatment with steroids had been stopped, however, she relapsed. Her haemoglobin concentration was $8.8 \mathrm{~g} / \mathrm{dl}$, white blood cell count $8 \cdot 7 \times 10^{9} / 1$, platelets $15 \times 10^{9} / 1$, reticulocytes $3 \%$, and erythrocyte sedimentation rate $130 \mathrm{~mm}$ in the first hour. Direct Coombs test yielded positive results. Antinuclear and anti-DNA antibodies were both negative. There was no haematuria or proteinuria to suggest any renal involvement. She was restarted on prednisolone at $2 \mathrm{mg} / \mathrm{kg} /$ day.

A week later she developed focal convulsions of left upper and lower limbs. Blood pressure was systolic $100 \mathrm{~mm} \mathrm{Hg}$ and diastolic $60 \mathrm{~mm} \mathrm{Hg}$. A computed tomogram of the brain showed an infarct in the right frontoparietal region. Lumbar puncture showed normal cerebrospinal fluid. She was thus diagnosed as having cerebral lupus and was pulsed with methylprednisolone $200 \mathrm{mg}$ daily for three days 